\title{
Pattern and outcome of penetrating chest injuries at the Emergency Management Center in Erbil City
}

\section{Abstract}

Background and objective: Trauma to the chest is a life-threatening condition because the chest contains many vital organs such as the heart, multiple blood vessels, and lungs. This study aimed to identify the pattern and outcome of the war-related penetrating chest injuries at the Emergency Management Center, Erbil, during the Islamic State in Iraq and Syria conflict.

Methods: This retrospective study involved 154 chest injured victims at the Emergency Management Centre in Erbil City. Data were collected from the Statistics Department of this hospital from June 2014 to July 2017.

Results: The mean (SD) age of the victims was $25.75 \pm 11.567$ years. The majority of the cases were young $(61 \%)$, male $(85.1 \%)$, Kurds $(72.1 \%)$, and injured outside Erbil governorate $(40.9 \%)$. The leading cause of injury was bullet injury $(74.7 \%)$. Provision of the first aid before admission was high (87\%). Most victims did not have any other injuries (66.9\%). Surgical operations were performed to the majority of victims $(93.5 \%)$. Most of them did not develop any complications $(78.6 \%)$, with only $21.4 \%$ of the cases had some complications. The development of the complications was significantly associated with the presence of other injuries $(68.6 \%$ vs. $83.5 \%, P=0.034)$.

Conclusion: During the Islamic State in Iraq and Syria related war in Iraq, chest injury by gunshot had increased. The Emergency Management Center provides a suitable medical service that helped in reducing complications and deaths. The development of complications was significantly associated only with the presence of multiple injuries.

Keywords: Patterns; Outcome; Penetrating; Chest injuries.

\section{Introduction}

Thoracic injury is one of the major critical injuries inflicted upon the body that is found to be the primary or a contributing cause of about a quarter of all trauma-related deaths. ${ }^{1}$ These objects that penetrate the human body lacerate, disrupt, destroy, and contuse tissue is often associated with a high risk of life-threatening two major vital organs lungs and heart intrathoracic organ injury. It also includes major vessels aorta, vena cava, and pulmonary vessels. ${ }^{2,3}$ The assessment and management of chest injury must be fast. At the beginning of injury, transferring, pre-operation even after and during anesthesia and need to admit to the intensive care unit (ICU) with moderate or severe chest injuries. ${ }^{4}$ When a patient complains from chest injury, and it is associated with the open airway and difficulty breathing has a tension requires rapid decompression and the insertion of a chest tube. ${ }^{5}$ Keneally and Szpisja reported in their study that was conducted in Iraq and Afghanistan in 2013 that penetrating injuries were the most common mechanism of injury as $10 \%$ of the injured patients in military operations sustained a thoracic injury with a mortality rate of $10.5 \% .{ }^{6}$ A cross-sectional study conducted by the Mohammad Zade et al. in Iran showed that complained $67 \%$ of chest injury victims had suffered from blunt trauma, and hemothorax was the most

${ }^{1}$ Department of Surgery, College of Medicine, Hawler Medical University, Erbil, I raq.

* Correspondence: rawand_haweizy@yahoo.com 
frequent complication. ${ }^{7}$ Demirhan et al. reported in their retrospective study during 10-years management and clinical outcome in Turkey that out of 4205 cases, $34 \%$ of the blunt injury were related to penetrating injury. ${ }^{8}$ Another study by Karaca et al. showed that among 142 patients; $90.1 \%$ were male, the mean age was 36 years, $99.4 \%$ had penetrating trauma hemothorax, and lung injuries were detected in 40\%. ${ }^{9}$ Aldahmashi 2015 in his retrospective study of 275 chest trauma cases in Yemen, reported that penetrating thoracic injuries represented $49 \%$, and $96.3 \%$ of the cases needed for intercostal tube and thoracotomy, $78.6 \%$ complained of dyspnea, $17 \%$ had hemorrhagic shock, $22.2 \%$ were extrathoracic injuries, only $3.3 \%$ had spinal cord injuries, $6.2 \%$ had brain injury, and $4.4 \%$ had intra-peritoneal injuries. ${ }^{10}$ In the prospective study of Atri et al. that included 2571 patients, $60 \%$ had a rib fracture, $51.7 \%$ had hemopneumothorax, $37.9 \%$ had surgical emphysema, $10.4 \%$ had lung contusion, $6.2 \%$ had flail chest, and $48.8 \%$ had associated injuries. ${ }^{11}$ According to a variety of references mentioned above, chest injury is one of the most serious and fatal injuries in the human body, especially penetrating the chest by bullet, shell, and mine. Therefore, this study aimed to identify the patterns and outcomes of war-related penetrating chest injuries admitted to the Emergency Management Center hospital during the Islamic State in Iraq and Syria (ISIS) conflict.

\section{Methods}

\section{Design and setting}

A retrospective study was carried out from the Emergency Management Centre (EMC) in Erbil City. We received the data from the Statistics Department of EMC.

\section{Participants}

The data was collected from the Statistics Department of EMC. We received the information of all patients that were admitted to the EMC in Erbil City between $1^{\text {st }}$ Jun 2014 and July 2017. A total of 154 cases of chest injury were registered at EMC that were admitted and remained at EMC in Erbil City for treatment during this period.

\section{Tool}

A questionnaire consisting of three parts was designed based on the information of the patients records. Part 1 included four questions about the socio-demographic characteristics; age, gender, ethnicity, and geographical area of injury. Part 2 consisted of seven clinical characteristics of injury; cause of injury, mechanism of injury, care before admission to the Emergency Hospital, provider of care before admission to the Emergency Hospital, mode of transport to the Emergency Hospital, medical history, and another injury. Part 3 was related to the outcome characteristics of injury; doing the operation, name of the operation, postoperative complications, and the name of complications.

\section{Data collection}

Data was collected from the statistical department of EMC by reviewing the records of the patients from June 2014 to July 2017.

\section{Ethical aspects}

The study protocol was approved by the Research Ethics Committee at the College of Medicine, Hawler Medical University. Institutional permission was obtained from the EMC to getting information from the Statistics Department of EMC.

\section{Data analysis}

Data were analyzed by the statistical package for the social sciences (version 23). Both descriptive and inferential statistics were used. Descriptive statistics involved calculating frequencies and percentages. For inferential statistics, the participants were categorized into those having the development of complications and no complications. The association between the demographic and clinical characteristics of the study participants and the development of complications of the patients was assessed by using the Chi-square test. A $P$ value of $\leq 0.05$ was 
Pattern and outcome of penetrating chest .......

Zanco J. Med. Sci., Vol. 23, No. (3), December, 2019 https:/ / doi.org/ 10.15218/ zjms.2019.053

considered statistically significant.

\section{Results}

Table 1 shows that the majority of the victims $(61 \%)$ were within the age group 15 -30 years old. The mean age (SD) of the patients was $25.75 \pm 11.567$ years (range 3-68 years). Most patients were male $(85.1 \%)$. The majority of victims $(72.1 \%)$ were Kurds. Most of the victims $(40.9 \%)$ were injured outside of Erbil governorate.

Table 1: Socio-demographic characteristics of the study participants.

\begin{tabular}{|c|c|c|c|}
\hline \multirow[t]{2}{*}{ Characteristic } & & \multicolumn{2}{|c|}{$n=154$} \\
\hline & & $\mathbf{F}$ & $\%$ \\
\hline \multirow[t]{4}{*}{ Age group } & $0-14$ & 21 & $(14)$ \\
\hline & $15-30$ & 94 & (61) \\
\hline & $30>$ & 39 & $(25)$ \\
\hline & $M \pm S D$ & \multicolumn{2}{|c|}{$25.75 \pm 11.567$} \\
\hline \multirow[t]{2}{*}{ Gender } & Male & 131 & $(85.1)$ \\
\hline & Female & 23 & $(14.9)$ \\
\hline \multirow[t]{2}{*}{ Ethnicity } & Arabic & 41 & $(26.6)$ \\
\hline & Kurdish & 111 & $(72.1)$ \\
\hline \multirow{3}{*}{$\begin{array}{l}\text { The geographical area of } \\
\text { injury }\end{array}$} & Erbil city & 44 & $(28.6)$ \\
\hline & Erbil districts & 47 & $(30.5)$ \\
\hline & Outside Erbil governorate & 63 & $(40.9)$ \\
\hline
\end{tabular}


Table 2 shows that the primary cause of injury of the patients was bullet injury, which represented $74.7 \%$. The mechanism of injury for most of them $(75.3 \%)$ was a gunshot. Most of the sample (87\%) received first aid before admission to the Emergency Hospital. Most of them (64\%) received care from the Directorate of Health before admission to the Emergency
Hospital. Regarding the mode of transport of patients to Emergency Hospital, the majority were transported by ambulance $(84.4 \%)$. Regarding the medical history, the majority of them $(96.1 \%)$ were healthy before the injury. Most injured patients $(66.9 \%)$ did not have another injury, but $33.1 \%$ had another injury in another area of the body.

Table 2: Clinical characteristics of the injury in the study participants.

\begin{tabular}{|c|c|c|c|}
\hline \multirow[t]{2}{*}{ Characteristic } & & \multicolumn{2}{|c|}{$\mathrm{n}=154$} \\
\hline & & $F$ & $\%$ \\
\hline \multirow[t]{4}{*}{ Cause of injury } & Bullet & 115 & $(74.7)$ \\
\hline & Shell & 35 & $(22.7)$ \\
\hline & Mine & 1 & $(0.6)$ \\
\hline & Unknown & 3 & $(1.9)$ \\
\hline \multirow[t]{4}{*}{ Mechanism of injury } & Gunshot & 116 & $(75.3)$ \\
\hline & Blast & 23 & $(14.9)$ \\
\hline & Fragment & 13 & $(8.4)$ \\
\hline & Unknown & 2 & $(1.3)$ \\
\hline \multirow{2}{*}{$\begin{array}{l}\text { Care before admission to the Emergency } \\
\text { Hospital }\end{array}$} & First aid & 134 & $(87)$ \\
\hline & Non given & 20 & $(13)$ \\
\hline \multirow{5}{*}{$\begin{array}{l}\text { Provider of care before admission to the } \\
\text { Emergency Hospital }\end{array}$} & Medicine Sans Frontiers & 9 & $(5.8)$ \\
\hline & Aspen & 1 & $(0.6)$ \\
\hline & Unknown & 3 & $(1.9)$ \\
\hline & None has given & 20 & $(13)$ \\
\hline & Directorate of Health & 121 & $(78.6)$ \\
\hline \multirow[t]{4}{*}{ Mode of transport to Emergency Hospital } & Military & 4 & $(2.6)$ \\
\hline & Private care & 19 & (12.3) \\
\hline & Ambulance & 130 & (84.4) \\
\hline & Unknown & 1 & $(0.6)$ \\
\hline \multirow[t]{2}{*}{ Medical history } & Healthy & 148 & (96.1) \\
\hline & Prior medical & 6 & (3.9) \\
\hline \multirow[t]{2}{*}{ Another injury } & Yes & 51 & (33.1) \\
\hline & No & 103 & $(66.9)$ \\
\hline
\end{tabular}


Table 3 shows the outcome characteristics of injury in the study participants. The majority of the study samples $(93.5 \%)$ had done an operation. Only $6.5 \%$ of them complained of simple chest injury but did not need any operations. Among 93.5\% of the chest inured patients, $33.1 \%$ had a thoracostomy tube (chest tube), and other procedures were done for other problems. The majority of them $(78.6 \%)$ did not have any complications from the operation, while $21.4 \%$ developed some complications, mainly empyema thoracic, which represented only $3.9 \%$. Around $83 \%$ completed hospital care after that discharged from the hospital. Only 1.9\% deceased during the hospital stay by cardiac arrest, brain death, and respiratory failure, and pulmonary embolism.

Table 3: Outcome characteristics of injury in the study participants.

\begin{tabular}{|c|c|c|c|}
\hline \multirow[t]{2}{*}{ Characteristic } & & \multicolumn{2}{|c|}{$n=154$} \\
\hline & & $\mathbf{F}$ & $\%$ \\
\hline \multirow[t]{2}{*}{ Operation done } & Yes & 144 & $(93.5)$ \\
\hline & No & 10 & $(6.5)$ \\
\hline \multirow{10}{*}{$\begin{array}{l}\text { Name of } \\
\text { operation (144) }\end{array}$} & Chest tube and other procedure is done for another problem & 51 & $(33.1)$ \\
\hline & Chest tube & 42 & $(27.3)$ \\
\hline & Other procedure is done for another problem & 24 & $(15.6)$ \\
\hline & Chest tube and Thoracotomy & 11 & $(7.1)$ \\
\hline & Remove of Foreign body & 7 & $(4.5)$ \\
\hline & Thoracotomy & 3 & $(1.9)$ \\
\hline & Chest tube and removal of foreign body & 3 & $(1.9)$ \\
\hline & Damage control and Thoracotomy & 1 & $(0.6)$ \\
\hline & Remove of Foreign body and Other procedure done for another problem & 1 & $(0.6)$ \\
\hline & $\begin{array}{l}\text { Chest tube, removal of the foreign body and Other procedure done for } \\
\text { another problem }\end{array}$ & 1 & $(0.6)$ \\
\hline \multirow{2}{*}{$\begin{array}{l}\text { Postoperative } \\
\text { complication }\end{array}$} & Yes & 33 & $(21.4)$ \\
\hline & No & 121 & $(78.6)$ \\
\hline \multirow{16}{*}{$\begin{array}{l}\text { Name of } \\
\text { complication (33) }\end{array}$} & Empyema thoracic & 6 & $(3.9)$ \\
\hline & Pneumothorax & 4 & (2.6) \\
\hline & Affecting skin and subcutaneous tissue & 3 & (1.9) \\
\hline & Lung Collapse & 3 & (1.9) \\
\hline & Infected Wound & 3 & $(1.9)$ \\
\hline & Empyema thoracic and affecting skin and subcutaneous tissue & 2 & (1.3) \\
\hline & Chest infection & 2 & $(1.3)$ \\
\hline & Hemopneumothorax & 2 & $(1.3)$ \\
\hline & Sepsis & 1 & $(0.6)$ \\
\hline & Intestinal obstruction & 1 & $(0.6)$ \\
\hline & Abdominal wound dehiscence & 1 & $(0.6)$ \\
\hline & Chest pain and Dyspnea & 1 & $(0.6)$ \\
\hline & Haemothorax & 1 & $(0.6)$ \\
\hline & The weakness of the lower limp & 1 & $(0.6)$ \\
\hline & Intrauterine death & 1 & $(0.6)$ \\
\hline & Chest effusion & 1 & $(0.6)$ \\
\hline \multirow[t]{4}{*}{ Discharge status } & Hospital care completed & 128 & $(83.1)$ \\
\hline & Left against medical advice & 10 & $(6.5)$ \\
\hline & Transferred for further care & 13 & $(8.4)$ \\
\hline & Death & 3 & $(1.9)$ \\
\hline \multirow{2}{*}{$\begin{array}{l}\text { Deceased during } \\
\text { the hospital stay }\end{array}$} & Yes & 3 & $(1.9)$ \\
\hline & No & 151 & $(98.1)$ \\
\hline \multirow[t]{3}{*}{ Cause of death } & Cardiac arrest & 1 & $(0.6)$ \\
\hline & Brain death & 1 & $(0.6)$ \\
\hline & Respiratory failure and pulmonary embolism & 1 & $(0.6)$ \\
\hline
\end{tabular}


Table 4demonstrates the association demographic and clinical characteristics between the demographic and clinical characteristics of the study participants and the development of complications. There was no significant relationship between the of the study with the development of complications in the study except for the presence of other injuries $(68.6 \%$ vs. $83.5 \%, P=0.034)$.

Table 4: Association between the demographic and clinical characteristics of the study participants and the development of complications.

\begin{tabular}{|c|c|c|c|c|c|c|c|}
\hline \multirow{3}{*}{ Characteristic } & \multicolumn{7}{|c|}{ Complications } \\
\hline & & \multicolumn{2}{|c|}{ Yes } & \multicolumn{2}{|c|}{ No } & \multirow[t]{2}{*}{ Total } & \multirow[t]{2}{*}{$P$ value } \\
\hline & & No. & $\%$ & No. & $\%$ & & \\
\hline \multirow[t]{2}{*}{ Gender } & Male & 28 & $(21.4)$ & 103 & $(78.6)$ & 131 & 0.969 \\
\hline & Female & 5 & $(21.7)$ & 18 & $(78.3)$ & 23 & \\
\hline \multirow[t]{3}{*}{ Age (years) } & $0-14$ & 6 & $(28.6)$ & 15 & $(71.4)$ & 21 & 0.610 \\
\hline & $15-30$ & 18 & $(19.1)$ & 76 & $(80.9)$ & 94 & \\
\hline & $31>$ & 9 & $(23.1)$ & 30 & $(76.9)$ & 39 & \\
\hline \multirow[t]{2}{*}{ Civilian/Combatant } & Civilian & 24 & $(22.9)$ & 81 & $(77.1)$ & 105 & 0.527 \\
\hline & Combatant & 9 & $(18.4)$ & 40 & $(81.6)$ & 49 & \\
\hline \multirow[t]{2}{*}{ Cause of injury } & Bullet & 24 & $(20.9)$ & 91 & $(79.1)$ & 115 & 0.772 \\
\hline & Shell & 9 & $(23.1)$ & 30 & $(76.9)$ & 39 & \\
\hline \multirow[t]{3}{*}{ Mechanism of injury } & Gunshot & 24 & $(20.7)$ & 92 & (79.3) & 116 & 0.421 \\
\hline & Blast & 7 & $(30.4)$ & 16 & $(69.6)$ & 23 & \\
\hline & Fragment & 2 & (13.3) & 13 & $(86.7)$ & 15 & \\
\hline \multirow{2}{*}{$\begin{array}{l}\text { Care before admission to } \\
\text { the Emergency Hospital }\end{array}$} & First aid & 29 & $(21.6)$ & 105 & $(78.4)$ & 134 & 0.867 \\
\hline & Non given & 4 & (20) & 16 & $(80)$ & 20 & \\
\hline \multirow{3}{*}{$\begin{array}{l}\text { Mode of transport to } \\
\text { Emergency Hospital }\end{array}$} & Military & 1 & $(25)$ & 3 & (75) & 4 & 0.973 \\
\hline & Private care & 4 & (20) & 16 & $(80)$ & 20 & \\
\hline & Ambulance & 28 & $(21.5)$ & 102 & $(78.5)$ & 130 & \\
\hline \multirow[t]{2}{*}{ Medical history } & Healthy & 30 & $(20.3)$ & 118 & $(79.7)$ & 148 & 0.082 \\
\hline & Prior medical & 3 & $(50)$ & 3 & $(50)$ & 6 & \\
\hline \multirow[t]{3}{*}{ Another injury } & Yes & 16 & $(31.4)$ & 35 & $(68.6)$ & 51 & 0.034 \\
\hline & No & 17 & $(16.5)$ & 86 & $(83.5)$ & 103 & \\
\hline & Total & 33 & & 121 & & 154 & \\
\hline
\end{tabular}




\section{Discussion}

During the ISIS related war in Iraq from 2014 to 2017, the major war occurred in and around Mosul City near Erbil City, and most of the injured persons were transferred to Erbil City emergency hospitals. EMC was the focal point and the main hospital for war-related injuries. As Erbil was considered safe and most hospitals in and around Mosul were out of use during this time, the main hospital or center to treat injury was EMC. EMC embraces all the patients that related to the firearm and blast injuries that is according to the policy of Erbil Governorate. This retrospective study was carried out in EMC in Erbil City and received all the thoracic injured patients during the ISIS war, excluding blunt and sharp injuries. Penetrating thoracic, abdominal, or combined injuries are a high risk of life-threatening and the most common cause of death, because of intra-abdominal or intrathoracic organ injury. ${ }^{11}$ Thoracic injured patients need to immediate transferring into the nearest Emergency Management Service to be treated at the minimal on-scene time. ${ }^{2}$ The majority of the study samples were within the age group of 15-30 years old, and most patients were male. In every war, the majority of cases may be young and male fighters because most areas of the world the event happened among young people, and they were active and ready to do everything in their daily life especially warfare. The study agreed with many studies. ${ }^{2,12-16}$ The primary ethnic group of the study sample was Kurds because of the majority of the Erbil population was Kurdish people. About geographical area of injury mostly was injured from outside of Erbil governorate, which is mainly due to the war with the ISIS was happened in the Mosul and around Erbil city and the mainly of the injured cases transferred to the Erbil because of the nearest place to the event. The major cause of injury was bullet injury followed by shell injury, while the mechanism of injury was mostly gunshot followed by blast injury. The study participants were injured cases during the ISIS related war in Iraq from 2014 to 2017. The findings of this study are similar to Ali, and Gali study, who demonstrated that the major mechanism of injury was gunshot and blast injuries. ${ }^{17}$ It also agrees with Mohan and Mohan study that showed that the high-velocity gun shot was associated with a larger area of lung parenchyma that leads to a higher incidence of empyema. ${ }^{18}$ However, the study disagrees with the observational prospective analytical study of Saeed et al. from Sudan who observed that the lowest mode of trauma was gunshot injury. ${ }^{19}$ Most of the study sample received medical services like first aid before reaching the EMC, and this serviced was primarily provided by the Erbil Directorate of Health. According to the plan of Erbil Directorate of Health, medical service teams exist in the center of Erbil city and around it. They provide first aid for all events and transfer the victims to the emergency by ambulance. This result agrees with Sheffy et al. study, which emphasized the importance of the time interval between incident and arrival at tertiary care centers, and during the first crucial hour after injury, many patients are being treated by emergency medical services providers or in the emergencydepartment. ${ }^{20}$ Regarding the medical history of the patients, the majority of victims were healthy before the injury as most of them were young as we collected our data during the ISIS related war in Iraq. War usually involves young and healthy persons. Lugo et al. reported in their systematic review study that the first step to be taken during injury is to receive a complete and detailed of review history of the case especially medical history, because of the direct effect on the immediate, comprehensive management during traumatic injury. ${ }^{5}$ The majority of the study sample had operations, and the commonest type of procedure was chest tube, as with resuscitation penetrating chest injuries need chest drain to relieve hemo-pneumothorax, and to prevent 
ongoing complications as in our study only $21.4 \%$. The result of this study was similar to the retrospective study of Chrysou et al., who reported that more than half of 110 polytrauma patients with blunt chest injury required a chest tube. ${ }^{21}$ It also supported by a retrospective review study conducted by Ali and Gali, 2004 on 78 patients over a three-year period in Maiduguri, Nigeria; The majority of their study sample required only chest tube as definitive treatment. ${ }^{17}$ The result was also supported by Pramod et al. study, which reported that only a small size of chest injury patients are managed conservatively without the need for a chest tube. ${ }^{22}$ The majority of the study group did not have any complications from the operation. Of those who developed complications, the major complication was empyema thoracic. Most of the study participants were healthy before the injury and received first aid during injury as soon as possible. The result was similar to Saeed et al. study, which reported a low complication rate among chest injured patients $(10.7 \%) .{ }^{19}$ Around $21 \%$ of the study sample complained of some complications, mainly empyema thoracic. This result was supported by Mohan and Mohan study, who reported an association between the high-velocity gunshot wounds with lung parenchyma contusion leading to a higher incidence of empyema. ${ }^{18}$ However, the result disagrees with Pramod et al., Freixinet et al., and Elmali et al. studies that showed that the major complication of penetrating chest injuries was hemothorax. ${ }^{13,23,24}$ The majority of the study sample completed the hospital care, then discharged from the hospital. This result was similar to the results of Dodia and Sansiya, who found that the majority of the study sample stayed at the hospital to complete medical care. ${ }^{2}$ Furthermore, it agrees with the prospective study of Kahn et al., in which all the 114 consecutive patients with chest trauma completed the hospital care and had a hospital stay of 8-76 days. ${ }^{15}$ Only three cases of the study deceased during the hospital stay by cardiac arrest, brain death, and respiratory failure, and pulmonary embolism. These deaths might be due to associated injuries and late arrival to the hospital and poor prehospital care. The low mortality is probably related to having the majority of victims arrived at EMC had no major organ injuries like heart, great vessels as difficult for such cases to reach hospital especially outside Erbil and also the majority of cases young and fit and other reason prehospital care and resuscitation. These findings agree with a quantitative analysis of the literature that was conducted by Bouzat et al. in France, which reported only one death related to neurological deficit. ${ }^{25}$ However, our findings disagree with the Peleg et al. study, which showed that $80 \%$ of deaths among the penetrating chest injury terror victims occurred within the first 24 hours of hospitalization. ${ }^{26}$ They also disagree with the retrospective study of Kumar et al. who reported that the majority of the victims of the penetrating chest injuries caused by firearms or sharp pointed weapons had died on the spot or within three hours. ${ }^{27}$ This study showed that there was no statistically significant relationship between the demographic and clinical characteristics of the study with the development of complications except the development of complications with other injuries. This result could be due to low postoperative complications. The result of this study was supported by the retrospective study of Tsai et al. 2017 from Taiwan, who reported no significant relationship between all inter-group differences. ${ }^{16}$ This result also agrees with the retrospective, cross-sectional study of the Moodley from South Africa, who reported no statistically significant difference between demographic characteristics of penetrating chest injured patients or presenting factors with the severity of the injury. ${ }^{28}$ However, it disagrees with a previous retrospective study, in which a statistically significant difference was found between the complications like mortality rates and 
penetrating injuries, and a significant difference was found between thoracic injury with other organ injuries. ${ }^{8}$

\section{Conclusion}

During the ISIS related war in Iraq from 2014 to 2017, penetrating chest injuries by gunshot increased. Most victims were male, young, and Kurds. Most cases were treated only by chest drain; few needed thoracotomy. The mortality and morbidity were low, and the majority of cases had pre -hospital care by the emergency service teams belonging to Erbil Directorate of Health. Most of the injuries were healthy and without a prior medical problem and not associated with multiple trauma. EMC provides suitable medical services by receiving cases and inserting a chest drain as soon as possible and thoracotomy for selected cases. All mortality cases were related to multi-trauma and late arrival and poor recitations before admission to EMC.

\section{Competing interests}

The author declares no competing interests.

\section{References}

1. Shah JV, Solanki MI. Analytic Study of Chest Injury. IJSS J Surg 2015; 1(1):5-9.

2. Dodia H, Sansiya K. A Study of Penetrating Thoracic and Abdominal Injuries. J Dent Med Sci 2015; 14(8):64-95.

3. Kumar BA, Chakravarthy GR, Bharath A. Blunt Trauma Chest: A Study on Clinical Pattern. J Dent Med Sci 2017; 16(3):1-7.

4. Lugo VW, Gastelum AS, Armas AH, Garnica FG, Gómez MG. Chest trauma: An overview. J Anaesth Crit Care Open Access 2015; 3(1):00082.

5. DeBakey ME. Emergency War Surgery. United States of America. $3^{\text {rd }}$ ed. U.S. revision; Library of Congress Cataloging-in-Publication; 2004. P. 224.

6. Mohammadzadeh M. Hosseinpour M, Mirzadeh AS, Jazayeri H, Arani MG. Chest Injury Evaluation and Management Two Major Trauma Centers of Isfahan Province, IR Ira. Arch Trauma Res 2012; 1(2):54-7.

7. Aghdas SA, Bazargan HS, Shabanineja $H$, Gor HA. Injury epidemiology in Iran: a systematic review. J Inj Violence Res 2017; 9(1):27-40.
8. Demirhana R, Onana B, Oza K, Halezeroglu S. Comprehensive analysis of 4205 patients with chest trauma: a 10-year experience. Interactive Cardiovasc Thorac Surg 2009; 9:450-3.

9. Karaca MA, Kartal ND, Erbil B, Öztürk E, Kunt MM, Şahin TT, et al. Evaluation of gunshot wounds in the emergency department. Ulus Travma Acil Cerrahi Derg 2015; 21(4):248-55.

10. Aldahmashi MN. Patterns of Chest Injuries among Yemeni patients: Aretrospective analysis. Yemeni J Med Sci 2015; 9:22-30.

11. Atri M, Singh G, Kohli A.Chest trauma in Jammu region an institutional study. Thorac Cardiovasc Surg 2006; 22:219-22.

12. Dodge I, Coskun A, Ozbay S, Bayram M, Atli B. Management of thoracic trauma in emergency service: Analysis of 1139 cases. Pak J Med Sci 2013; 29(1):58-63.

13. Hemmati $H$, Leili EK, Amiri ZM, Darzi AA, Kiakalayeh AD, Moghaddam AD, et al. Evaluation of chest and abdominal injuries in trauma patients hospitalized in the surgery ward of Poursina Teaching Hospital, Guilan, Iran. Arch Trauma Res 2013; 1(4):161-5.

14. Mohta M, Kumar P, Mohta A, Bhardwaj R, Tyagi A, Sethi AK. Experiences with chest trauma: Where do we stand today? Indian J Crit Care Med 2006; 10(1):25-8.

15. Khan IA, Ghaffar S, Asif S, Rehman Z, Asad S, Ahmed E, et al. Management of thoracic trauma: Experience at Ayub Teaching Hospital, Abbottabad. J Ayub Med Coll 2009; 21(1):1524.

16. Tsai YM, Lin KH, Huang TW, Chen CY, Hong ZJ, Hsu SD. Outcomes of patients with blunt chest trauma encountered at emergency department and possible risk factors affecting mortality. J Med Sci 2017; 37(3):97-101.

17. Ali N, Gali BM. Pattern and management of chest injuries in Maiduguri, Nigeria. Ann Afr Med 2004; 3(4):181-4.

18. Mohan PV, Mohan R. Management of warfare chest injuries. Med J Armed Forces India 2011; 66(4):329-32.

19.Saeed AY, Hamza AA, Ismail OM. Pattern and management outcome of chest injuries in Omdurman Teaching Hospital Sudan. Global J Med Res 2015; 15:1.

20. Sheffy N, Chemsian RV, Grabinsky A. Anaesthesia considerations in penetrating trauma. Br J Anaesth 2014; 113(2):276-85.

21. Chrysou K, Halat G, Hoksch B, Schmid RA, Kocher GJ. Lessons from a large trauma center: impact of blunt chest trauma in polytrauma patients still a relevant problem? Scand J Trauma Resusc Emerg Med 2017; 25(1):42.

22. Pramod T, Shashirekha CA, Chandan KR, Harsha R. Role of conservative management of traumatic chest injuries: A retrospective study and review of literature. Int J Sci Stud 2015; 3(8):147-50. 
23. Freixinet J, Beltrán J, Rodríguez PM, Juliá G, Hussein M, Gil R, et al. Indicators of severity in chest trauma. Arch Bronconeumol 2008; 44(5):257-62.

24. Elmali M, Baydın A, Nural MS, Arslan B, Ceyhan $M$, Gürmen N. Lung parenchymal injury and its frequency in blunt thoracic trauma: the diagnostic value of chest radiography and thoracic CT. DiagnInterv Radiol 2007; 13:179-82.

25. Bouzat P, Raux M, David JS, Tazarourte K, Galinski M, Desmettre T.Chest trauma: First 48 hours management. Anaesth Crit Care Pain Med 2017; 36:135-45.

26. Peleg K, Daniel LA, Michael M, Shapira SC, Israel Trauma Group. Patterns of injury in hospitalized terrorist victims. Am J Emerg Med 2003; 21(4):258-62.

27. Kumar A, Verma AK, Srivastava AK. Penetrating chest injuries: A medicolegalanalysis. J Indian Acad Forensic Med 2007; 32(1):34-6.

28. Moodley $\mathrm{P}$. The profile of penetrating chest injuries in the South African private sector; 2016. (Accessed Oct 18, 2018, at: http://wiredspace.wits.ac.za/bitstream/ handle/10539/22576/M Med\%20 F inal\% 20Report.pdf?sequence=1\&isAllowed=y). 